\title{
Sorption of Linear Alkylbenzene Sulfonate (LAS) onto El-Mex Bay Sediments, Mediterranean Sea, Egypt
}

\author{
Mohamed Abd El-Aziz Okbah ${ }^{1,}$, , Abd El-Monum Mohamed Ibrahim², Mohamed Nazieh Gamal ${ }^{1}$, \\ Edweb Ali Salem Dango ${ }^{3}$
}

${ }^{1}$ National Institute of Oceanography \& Fisheries, Kayet Bay, Alexandria, Egypt

${ }^{2}$ Department of Chemistry, Faculty of Science, Alexandria University, Alexandria, Egypt

${ }^{3}$ High Institute in Jerpoly area, Tripoli, Libya

\section{Email address:}

m_okbah@yahoo.com (M. A. Okbah),Abdelm1944@yahoo.com (A. M. A. Ibrahim), chem_mnazieh@yahoo.com (M. N. Gamal), dwiebi_dango@yahoo.com (E. A. S. Dango)

\section{To cite this article:}

Mohamed Abd El-Aziz Okbah, Abd El-Monum Mohamed Ahmed Ibrahim, Mohamed Nazieh Gamal, Edweb Ali Salem Dango. Sorption of Linear Alkylbenzene Sulfonate (LAS) onto El-Mex Bay Sediments, Mediterranean Sea, Egypt. Science Research.

Vol. 3, No. 3, 2015, pp. 110-121. doi: 10.11648/j.sr.20150303.21

\begin{abstract}
The objective of this work is to study the sorption behavior of Linear Alkylbenzene sulfonate (LAS) onto El-Mex Bay sediments. The Bay is a part of Alexandria coast on the Mediterranean Sea located in Northern Egypt. The study showed homogenous distributions of LAS homologues in El-Mex Bay sediments. The range of the LAS concentration in sediments was between 0.370 and $0.540 \mu \mathrm{gg}^{-1}$ dry solids. High total LAS concentrations in the bay sediments coincide with small amounts of DO (0.5-1.9 $\left.\mathrm{mgl}^{-1}\right)$ and low Eh values. The LAS homologues were usually detected between 10 and 13 carbon atoms, with $\mathrm{C}_{11^{-}}$ and $\mathrm{C}_{12}$-LAS; they are the most adsorbed on the bay sediments. Sorption experiments on the Bay sediments were performed with different organic matter content (ranged from 0.9 to $1.16 \%$ ) and were applied at different $\mathrm{pH}$ values (3.8, 8.5 and 12). The sorption behavior of LAS on El-Mex Bay sediments is satisfactory described by the Freundlich and Stern-Graham isotherm equations. Based on the data presented in this work, the following conclusion was drawn: Sorption distribution coefficients were significantly increased with the increasing the organic matter content due to the hydrophobic interaction between the alkyl chain and organic carbon content of the sediment. LAS sorption on sediments was strongly affected by $\mathrm{pH}$ and decreased with increasing $\mathrm{pH}$ value for each sediment sample which can be attributed either to electrostatic interactions or to specific chemical interactions.
\end{abstract}

Keywords: Linear Alkylbenzene Sulfonate, Sorption, LAS, El-Mex Bay, Sediments

\section{Introduction}

El-Mex Bay is a part of Alexandria coast on the Mediterranean Sea, it is adjacent to Alexandria City center that is populated with about six million inhabitants, in addition it consider as one of the main fishing sources in Egypt. The contaminants are introduced through waterway and through several land based sources into the Bay. Surfactants are widely used in household and industrial products. After use, surfactants as well as their products are mainly discharged into sewage treatment plants and then dispersed into the environment through effluent discharge into surface waters and sludge disposal on lands. Surfactants have different behavior and fate in the environment. Nonionic and cationic surfactants had much higher sorption on soil and sediment than anionic surfactants such as linear alkylbenzene sulfonates (LAS). Most surfactants can be degraded by microbes in the environment although some surfactants such as LAS and alkylphenols may be persistent under anaerobic conditions [1]. The world production of synthetic surfactants in 2003 reached to 18.2 million tons [2]. LAS are the most popularly used synthetic anionic surfactants. It has been extensively used for over 30 years with an estimated global consumption of 3.9 million tons in 1998 [3]. Commercially available products are very complex mixtures containing homologues with alkyl chains ranging from 10 to 14 carbon atoms $\left(\mathrm{C}_{10^{-}} \mathrm{C}_{14}\right)$. LAS were found to degrade in sludge amended soils with a half-life of 7 to 33 days. Most surfactants are not acutely toxic to 
organisms at environmental concentrations and aquatic chronic toxicity of surfactants occurred at concentrations usually greater than $0.1 \mathrm{mgl}^{-1}$ [1]. LAS is used in nearly all kinds of detergents and cleaning preparations including laundry powders, laundry liquids, manual dishwashing liquids, detergent tablets, soap bars, and household cleaners. The amounts of LAS used in detergents vary up to $30 \%$ of the weight of the total product. Linear alkylbenzene sulphonates (LAS) consist of an alkyl chain attached to a benzene ring in the para position to the sulfonate group. Sometimes toluene, xylene and naphthalene are used in place of benzene. The homologue distributions in commercial products cover alkyl chain lengths from $\mathrm{C}_{10}$ to $\mathrm{C}_{14}$ with an average chain length of $\mathrm{C}_{11.7}$. Abd-Allah (1995)[4] determined the LAB concentration in sediment samples from Alexandria coast using a high resolution (capillary) gas chromatograph equipped with flame ionization detector (FID). The LAB content in El-Mex Bay sediments were $3.8 \mu \mathrm{g} / \mathrm{g}$ (dry sediment) with relative abundance 5:26:37:20:12 for $C_{10}, C_{11}, C_{12}, C_{13}$ and $C_{14}$, respectively. The parent linear alkylbenzene (LAB) which may be present in commercially produced LAS at concentrations of $1-3 \%$ [5]. The ratio of concentration of LAB: LAS in El-Mex Bay sediments around of 10:1 it can be attributed to the half life for precursor compounds $\mathrm{LAB}$ was greater than half life for LAS as well as El-Mex region in Alexandria city characterized by the broadness of petrochemical plants that produced this type of compounds. Theoretically, the surfactants can be degraded and removed by chemical, physical and biological processes in wastewater treatment plants [6]. However less than $5 \%$ of all municipal wastewater is treated by wastewater treatment plants in Egypt. Large quantities of surfactant residues in wastewater are discharged into the lakes, rivers and seawaters. Pollution problems of El-Mex Bay in Alexandria are well known, but no enough studies have reported the distribution and concentrations of surfactant residues and their degradation products in the aquatic environment. Knowledge of the processes involved in distributing organic micro-contaminants among ecosystem compartments is essential to an understanding of their behavior in the environment. This is particularly important in the case of linear alkylbenzene sulfonate (LAS), due to their frequent use as surfactants in detergents and other cleaning products [7]. LAS sorption on natural sediments is known to occur widely. Most published studies have been carried out using riverine sediments [8,9] or soil components, principally metallic oxides and clays [10]. Similar studies have been performed with non-ionic surfactants [11]. These studies have provided answers to many important questions: thus, the relation between chemical structure of LAS and its sorption capacity [12], and the influence of the nature of the sediment on LAS sorption. A theoretical model for sorption has been proposed by Di Toro et al. (1990)[13] and validated in field studies [14]. Modeling the LAS sorption phenomenon may allow one to estimate the proportion of discharged surfactant that is removed from the water column and accumulated in compartments where its degradation rate is substantially different [15]. Most of the sorption work of LAS onto sediments has been conducted in fresh water systems. There is a complete lack of sorption work in sea water systems [16].The difference in physico-chemical properties, biodegradability, partitioning and distribution explains the observed differences between the mass fluxes of different surfactants. The main objective of the present work is to highlight the effect of $\mathrm{pH}$ and total organic matter on the adsorption processes of the anionic surfactant (linear alkylbenzene sulfonate; LAS) in relation to different sediments collected from El Mex Bay.

\section{Material and Methods}

\subsection{Study Area}

El- Mex bay is one of the main fishing grounds of Alexandria located between longitude $29^{\circ} 47.1^{\prime}$ to $29^{\circ} 50.4^{\prime} \mathrm{E}$ and latitude $31^{\circ} 7.5^{\prime}$ to $31^{\circ} 9^{\prime} \mathrm{N}$ (Figure1). It represent a shallow sheltered Estuary west of Alexandria, extends for about $15 \mathrm{~km}$ between El-Agamy headland to the west to the Western Harbor to the east and from the coast to a depth of about $30 \mathrm{~m}$. The Bay has a mean depth of $10 \mathrm{~m}$. Its surface area is about $19.4 \mathrm{~km}^{2}$ and its volume $190 \times 10^{6} \mathrm{~m}^{3}$. It receives a heavy load of waste water $\left(2.6 \times 109 \mathrm{~m}^{3} \mathrm{year}^{-1}\right)$ both directly from industrial out falls and indirectly from Lake Mariut via El-Mex pumping station.

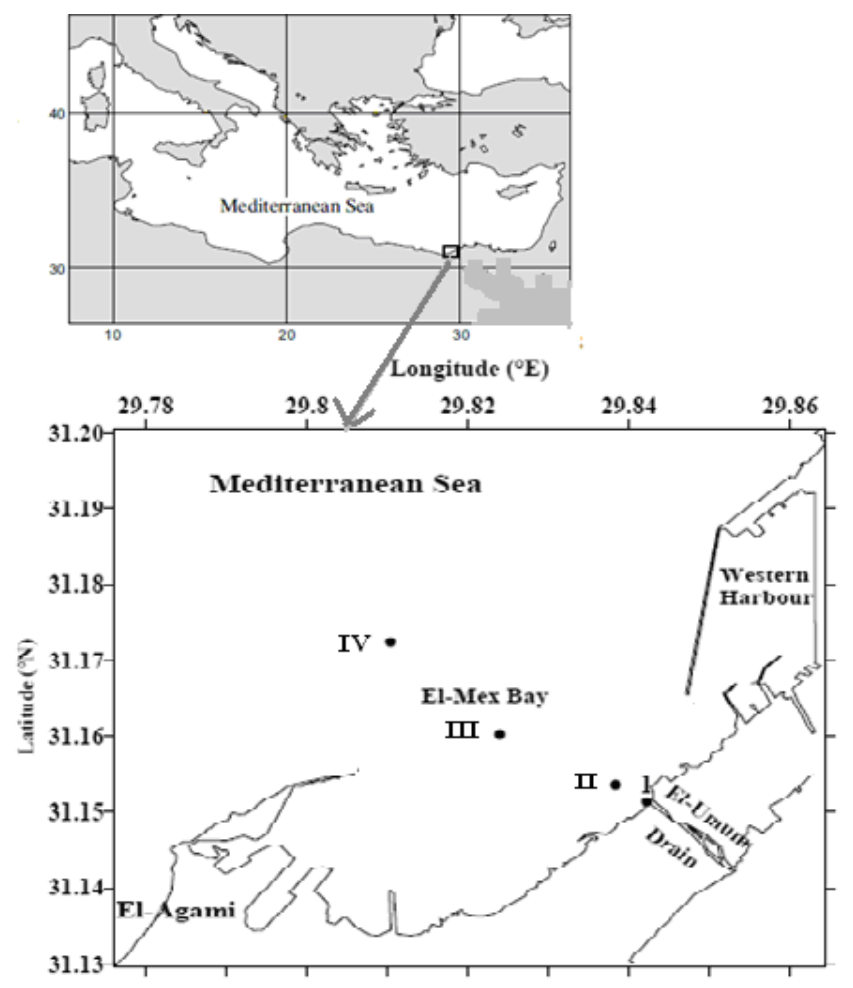

Figure 1. Map of sampling Stations.

\subsection{Sampling and Analyses}

Four Surficial sediments were collected in April 2013 Using Ekman grab sampler. One kg of sediment materials with a penetration depth of about $20 \mathrm{~cm}$ was collected. The material 
selected for analysis was taken from the middle part of the sediment materials, which was not in direct contact with the metal surface of the sampling device. The samples were sliced from the grab center placed in glass bottles, which were pre-acid washed with $(1: 1 \mathrm{HCl})$ and rinsed with distilled water. Total organic carbon (TOC \%) was determined according to Walkley-Black's wet oxidation method with potassium dichromate in acidic environment according to Baruah and Barthakur (1997) [17]. The pH and Redox potential (Eh) were applied to the sediments to stimulate anaerobic conditions. Eh was measured in situ using a portable digital $\mathrm{pH} / \mathrm{mV}$-meter from HACH model EC10.

\subsection{Analysis of LAS in Seawater}

Rapid determination of anionic surfactants (AS) by improved spectrophotometer method using methylene blue (MB), as cationic dye, was performed by Koga et al. (1999)[18]. The method based on the reaction between linear alkylbenzene sulfonate (LAS), as anionic surfactants, and methylene blue (MB), as cationic dye, to form associated ion-pair (LAS-MB ion pair) in water with 1:1 molar ratio which can be easily extracted to the organic phase (chloroform, $\mathrm{CHCl}_{3}$ ).

\subsection{Determination of LAS in Sediment Samples by RP-HPLC}

The determination of linear alkylbenzene sulfonate using reversed phase high performance liquid chromatography was performed according to Akyüz and Robers [19], (2002) and Gonzalez-Mazo et al. (1997)[20]

\subsubsection{LAS Isolation from Sediment Samples}

Quantities of air-dried sediment samples $(\sim 20 \mathrm{~g})$ were extracted for $12 \mathrm{~h}$ using Soxhlet apparatus with $200 \mathrm{ml}$ of methanol and $20 \% \mathrm{w} / \mathrm{w}$ solid $\mathrm{NaOH}$ mixed with the sample. Subsequently the methanolic extracts were evaporated to 2-4 $\mathrm{ml}$ in a rotary evaporator and transferred into a $100 \mathrm{ml}$ beaker. The round-bottom flask was rinsed twice with hot methanol in order to obtain the compounds of interest, which were then added to the beaker. The combined extract was dried under a gentle stream of nitrogen. The dried residue containing LAS that isolated from the sediment extract was dissolved by ultrasonication for 5-7 $\mathrm{min}$ in 5-10 ml methanol/water (30:70). The extract was made up to a known volume prior to HPLC analysis. This solution was neutralized with $\mathrm{HCl}(\mathrm{pH} 4-7)$ and ultrasonicated again for at least one min to dissolve sodium chloride. The extraction and derivatization procedures for the determination of LAS residues in the sediment samples are summarizes in Figure 2.

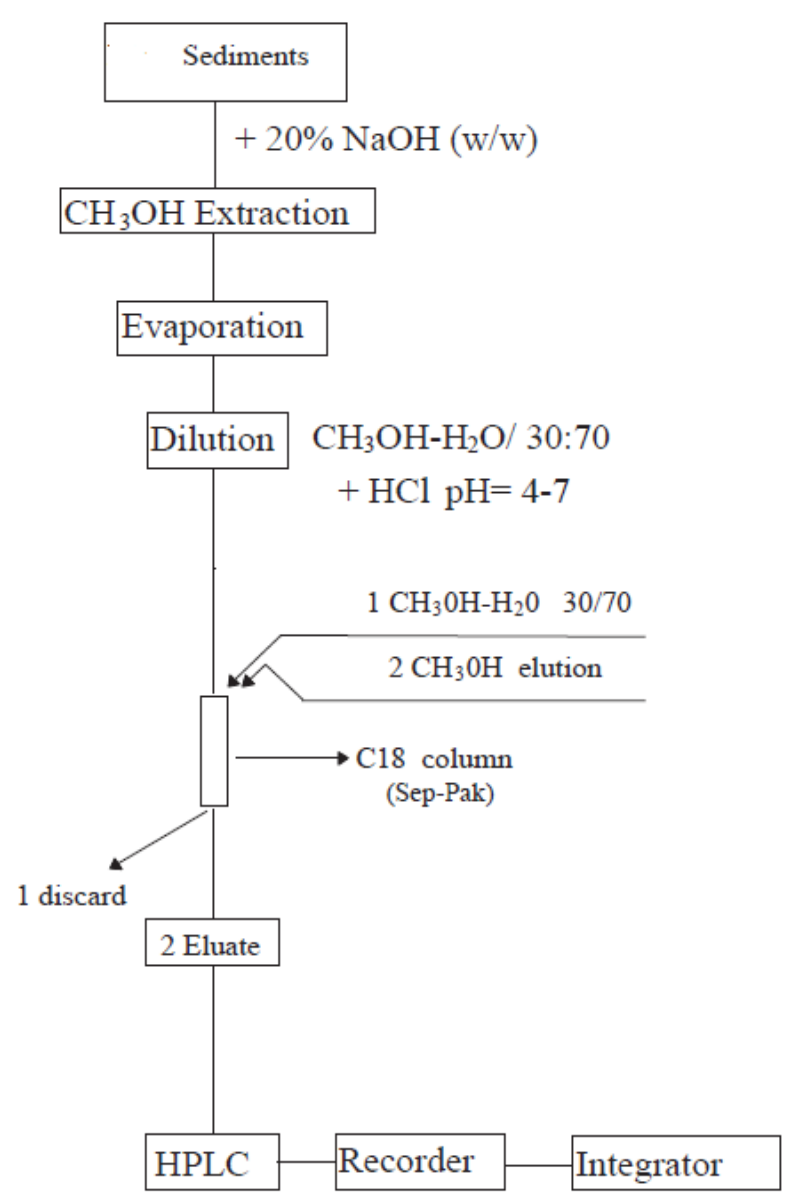

(Akyüz and Robers, (2002) [19])

Figure 2. Flow chart of HPLC determination of LAS Sediment. 
Solid-phase extraction procedure: The process of solid-phase extraction (SPE) was performed using $\mathrm{C}_{18}$ cartridge. The $\mathrm{C}_{18}$ cartridge was preconditioned with $5 \mathrm{ml}$ of methanol and $5 \mathrm{ml}$ of deionized water before use. The column was not allowed to become dry. Half the sonicated solution was percolated through the $\mathrm{C}_{18}$ column at a flow rate of $2 \mathrm{ml}$ $\min ^{-1}$. The column was washed with $5 \mathrm{ml}$ of deionized water. LASs were eluted with $15 \mathrm{ml}$ of methanol. The methanolic eluate was evaporated to half of its original volume under a gentle stream of nitrogen on a boiling water bath and diluted to a known volume with water containing $0.005 \mathrm{M}$ SDS and the final ratio adjusted to 50:50 methanol/water. This solution was injected into the HPLC system. The methanol/water proportion in the solution to be cleaned was used by suitably modifying methods previously reported by Comellas et al. (1993)[21].

HPLC apparatus and conditions; the analytical method in this work was performed on an Aglint Model 1100 liquid chromatography consisting of a quaternary pump with a 100 $\mu 1$ loop injector The detector was operated at wavelength 225 $\mathrm{nm}\left(\lambda_{\max }\right)$, with a spectral band pass of $10 \mathrm{~nm}$. The chromatographic separation was performed in the reversed-phase mode by using an octadecylsilica column (Zorbax ODS $\mathrm{C}_{18}, 250$ x $4.6 \mathrm{~mm}$ I.D., $5 \mu \mathrm{m}$ particle size, from Thermo Hypercil) equipped with a guard column and operated at room temperature. Elution was carried out at a flow rate of $1.0 \mathrm{ml} \mathrm{min}^{-1}$, using water-acetonitrile as a mobile phase (50:50) and $0.1 \mathrm{M} \mathrm{NH}_{4} \mathrm{ClO}_{4}$ as a phase modifier. The $\mathrm{pH}$ adjusted to 4.0 in order to protonate the surfactant sulphonic group, to increase the affinity for the stationary reversed phase.

Quantification: The compounds of interest were quantified by peak area using calibration graphs. The calibration graphs were obtained by dissolving in deionate water $5 \times 10^{-4}-6 \times 10^{-3}$ $\mathrm{mg} \mathrm{ml}^{-1}$ of standard LAS. LAS biodegradation products (SPCs) were eluted as single peak at the first few minutes of retention time of chromatogram graphs because SPCs more polar than LASs and have less affinity for the solid phase

\subsubsection{Experimental LAS Sorption onto El-Mex Bay Sediments}

Four sediment samples were collected from different stations, which are different in organic matter concentrations. The sediments were air-dried and passed through a $300 \mu \mathrm{m}$ mesh sieve. Prior to their use, sediments were kept in a refrigerator at $4{ }^{\circ} \mathrm{C}$. The sediments used in this study were coarse and medium sand proved by the grain size analysis of sediment samples. Unpolluted sea water used in the present study were collected from the deep well open sea of Alexandria West (free from anionic surfactants; LAS). The sea water was filtered through a $0.45 \mu \mathrm{m}$ Whatman membrane filter paper and kept in a refrigerator at $2{ }^{\circ} \mathrm{C}$ prior to its use.

Linear alkylbenzene sulfonate (LAS) was obtained from Hinkel Detergents and Chemicals Co, (purity >95\%) in the form of sodium salt. Fresh aqueous standard solutions of these anionic surfactants were prepared in sea water. LAS determined rapidly by improved spectrophotometer method using methylene blue [18].

(i) Kinetic experiments:

To determine the contact time between sediments and LAS-sea water solutions, the rate of LAS sorption onto sediments was determined. $0.6 \mathrm{~g}$ sediments (d.w) were shaken with $100 \mathrm{ml}$ of $10 \mathrm{mgl}^{-1}$ LAS solution for various periods of time. The phases can be separated by filtration through a 0.45 $\mu \mathrm{m}$ filter paper, then the first portion of the filtrate was discarded where the LAS in second portion of $50 \mathrm{ml}$ filtrate was determined. The amount of LAS sorbed was determined by difference between the initial and the equilibrium concentrations. The equilibrium time determined from the rate experiments was applied in the isotherm experiments.

(ii) Isotherm experiments:

For the isotherm experiments, $50 \mathrm{ml}$ of LAS solution in sea water with appropriate salinity, ranging in concentration from 1 to $100 \mathrm{mgl}^{-1}$ were added to $3.0 \mathrm{~g}$ (d.w) of sediment in a Teflon-stopper Pyrex bottles. The suspensions were adjusted to appropriate $\mathrm{pH}$ values $(3,8$ and 12$)$ with dilute $\mathrm{NaOH}$ or $\mathrm{HCl}$ solution and subsequently placed on shaker for 5 hours at $25{ }^{\circ} \mathrm{C}$. Filtration was carried out to obtain a clear solution for the determination of LAS. The amount of sorption was expressed as mg LAS per $g$ of dry sediment.

\section{Results and Discussion}

\subsection{Physicochemical Characteristics of El-Mex Bay}

\subsubsection{Water Characteristics}

In present study, salinity is used as indicator to reflect changes resulting from the mixing of fresh and seawaters. Salinity of El-Mex Bay was mostly affected by the amount of drainage water of El-Umum drain and the rate of exchange with the adjoining open sea. Salinity values showed a big variation according to the distance of the different sites from the effluents. The minimum surface salinity (3.71 practical salinity unit (PSU)) was observed within El-Umum Drain at station I and the maximum (38.5 PSU) found at the open sea stations (stations III and IV).

The $\mathrm{pH}$ value ranged between 7.74 and 8.14 . The lower $\mathrm{pH}$ was recorded at station I (inside El-Umum Drain) and station II (near El-Umum Drain). This explains the effects of different effluents in the surface water of El-Mex Bay.

Dissolved oxygen is considered as one of the most important and useful parameters for the identification of different water masses In El-Mex Bay, the values of DO fluctuated between the minimum of 1.27 and maximum of $2.33 \mathrm{mgl}^{-1}$ at stations I and IV, respectively. Generally, stations I, and II of the bay showed low DO levels, and these stations are located inside and near El-Umum Drain.

The result of anionic surfactant (LAS) in El-Mex Bay waters are shown in Table1, Station I was selected to check for El-Umum Drain contribution, as water enters the bay as illustrated in Figure1. It is observed that station I had the maximum LAS concentrations, ranged from 0.17 to $0.40 \mathrm{mgl}^{-1}$ LAS, while the other stations (II, III and IV) had low content 
comparing with station I, and ranged between 0.04 and 0.10 mg LAS L ${ }^{-1}$.

\subsubsection{Sediment Characteristics}

The results of physicochemical characterization of the sediments are presented in Table1. Sediments grain size of the study area revealed the dominance of the sand fraction. The total organic carbon (TOC) contents were low, ranged from $0.90 \%$ at station IV and increased to 1.16 at El-Umum Drain (Station I). The results showed differences in the distribution of $\mathrm{CaCO}_{3} \%$., ranged from $88 \%$ at El-Umum Drain (Station I) and $95 \%$ at stations III and IV. The lowest value of $\mathrm{pH}$ was found in the marine sediments at stations I (inside El-Umum Drain) and II (near El-Umum Drain) and slightly increased at station III and IV.

\subsection{LAS Distribution in El-Mex Bay Sediments}

Owing to their hydrophobic moiety LAS homologues show a significant affinity for suspended particles, this result in a widespread presence of surfactant residues in aquatic sediments and biota [22]. In general LAS concentrations are low for the various estuaries, although relatively high levels of these compounds were detected in specific zone which are close to waste water discharge outlets that reduce the degree of dilution of effluent. Sediments store information about environmental contaminants, which settled to seawater bottom while adsorbed to particulate matter. Such chemicals include heavy metals, lipophilic organic pollutants, and so-called amphiphilic surfactants and their lipophilic degradation products. Sediment samples that collected from El-Mex Bay were tacked from the stations that near to El-Umum Drain discharge outlet (Figure1) because the sediments at these stations are sandy fraction while, the rest of stations are rocky where the sediments collection are so difficult using in our experiment. The LAS concentrations detected for the sediments from four stations, which are close to El-Umum Drain discharge outlet (stations I, II and III) and municipal wastewater discharge outlets (Station IV, presence of untreated municipal wastewater effluent from the nearby population center), the LAS concentration ranged between 0.370-0.540 $\mathrm{ggg}^{-1}$ dry weight (Table 2). Physicochemical characterization and LAS homologues concentration in El-Mex Bay sediments are shown in Tables 1 and 2.

In the present study, the LAS homologues were detected between 10 and 13 carbon atoms, with $C_{11}$ and $C_{12}$ being the most abundant, this is agreement with the most literatures that concerned with the distribution of LAS homologues in seawater and sediment samples in different environmental compartments [5,23]. These homologues as "key intermediates" since they are the most adsorbed on solid phases and persistent in the LAS biodegradation process. The average percentage of carbon atoms from $\mathrm{C}_{10}-\mathrm{C}_{13}$ alkyl homologues of LAS in El Mex bay sediments is shown in Fig. 2 and indicates no major differences in homologue distribution in the four sediment samples I, II, III and IV (Figure3).

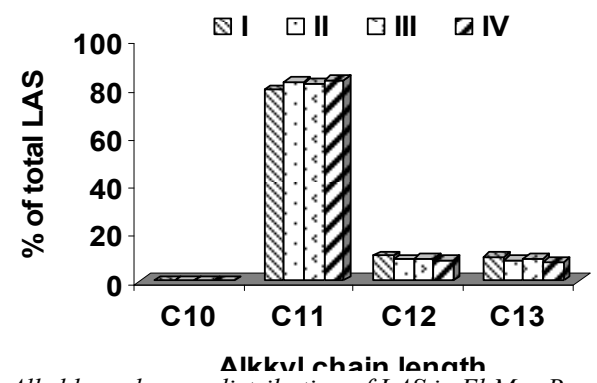

Figure 3. Alkyl homologues distribution of LAS in El Mex Bay sediments.

The results show a great affinity of LAS for the solid phase, as well as an increase in adsorption in line with increased chain length, this being evidence of a hydrophobic-type interaction. For example, $\mathrm{C}_{11}$-LAS constitute more than $75 \%$ of total LAS in all the samples, reaching $83 \%$ at station I, characterized with relatively high organic carbon content. This behavior has been previously described for different estuarine and marine ecosystems [24,25] and also for laboratory experiments for the same media [7]. There are several parameters must be taken into account in considering the process of LAS adsorption. Organic carbon content is one of the most important parameter which effect on the rate of LAS adsorption onto marine sediment as described earlier by experimental work in this research. Table 2 shows the percentage for each homologue constituting of total LAS in the sediment samples.

The variations in the total LAS $\left(\mathrm{C}_{10}-\mathrm{C}_{13}\right)$ concentrations in El-Mex Bay sediments were shown in Figure4. The maximum LAS concentrations were detected close to El-Umum drain discharge outlets (station I) and close to each population nucleus and decrease with the distance from the drain discharge outlets.

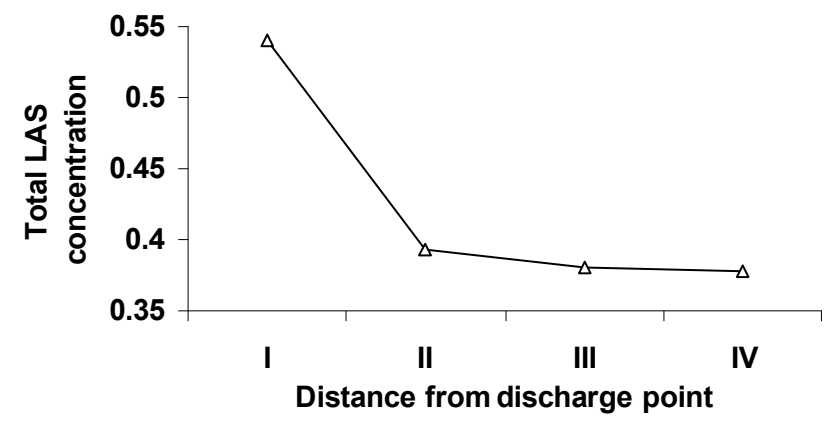

Figure 4. Spatial distribution of total LAS concentration in $\mu g^{-1}\left(C 10-C_{13}\right)$, El Mex Bay sediments.

The amount of dissolved oxygen may be considering a one of important factors that illustrate why the total LAS concentration at station I was greater magnitude order than that obtained at the rest of stations, where the low values of dissolved oxygen concentration at station I (average value; $1.27 \mathrm{mgl}^{-1}$ ), during the period of study, so we hypothesized that LAS persists at these regions due to oxygen limitation, despite the presence of acclimated indigenous microbial populations and the LAS homologues may be undergoes anaerobic biodegradation, while the oxidizing conditions at 
the rest of stations $\left(>5.0 \mathrm{mgl}^{-1}\right)$ encouraged bacterial action on organic compounds easily biodegradable in such conditions. Dissolved oxygen limitation indicates anaerobic biodegradation conditions, this evidence can be supported by low Eh-values at El-Umum Drain outlet (at station I, arround100). According to Elsgaard, et al. (2003) [26], the aerobic LAS biodegradation pathways undergo by successive $\omega$ - and $\beta$-oxidation, while a complete anaerobic LAS biodegradation mechanism is still unknown.

Generally, a high concentration of LAS homologues is consistent with the large population and industrial activities established in Alexandria city as well as the hydrophobic of compounds certainly plays an important role in their partitioning between bottom water and sediment [27]. In both seawater and sediments, it can be observed that the evolution of total LAS concentrations in solids is similar to found in seawater. An increase is seen in the process of adsorption onto sediments, in line with an increase of LAS in seawater. Gonzalez-Mazo et al. (2002)[23] reported that there is an increase in rate of adsorption process onto suspended solids, in line with the chain length for each additional carbon atom in the alkylic chain; the adsorption is between 2.5 and 3.2 times greater.

\subsection{LAS Sorption on El-Mex Bay Sediments}

\subsubsection{Kinetic Experiments}

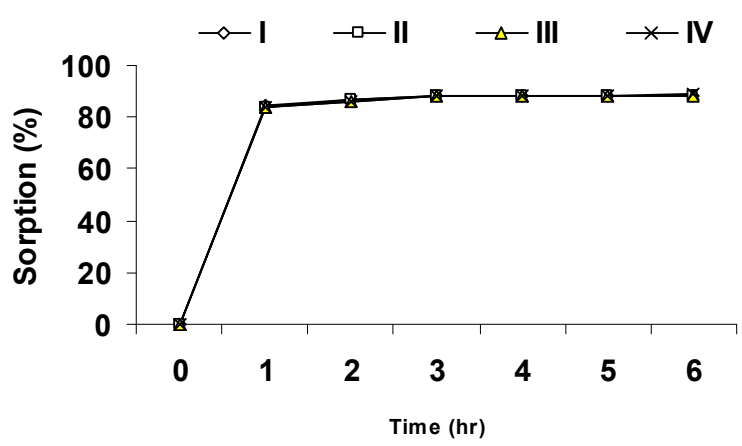

Figure 5. Rate of LAS sorption onto El Mex Bay sediments.

The rate of LAS sorption onto El-Mex bay sediment was determined by agitation of the LAS seawater-sediment mixture sediment sample, for respectively $0.5,1,2,3,4,5$ and 6 hours. Data for the rate of sorption of a $10 \mathrm{mgl}^{-1}$ solution (initial concentration, $\mathrm{C}_{\mathrm{i}}$ ) of LAS by $0.6 \mathrm{gl}^{-1}$ of the four sediments samples (Stations I, II, III and IV) (Table 4). The sorption of LAS is a fast phenomenon; under the conditions of experiment, all systems achieved equilibrium with 4 hours of contact time as illustrated in Figure5, these results are in agreement with literature for adsorption of linear alkylbenzene sulfonate (LAS) on marine sediments and soils [28] and adsorption of organic substances on activated sludge [29]. The amount of LAS degraded during this time of experiments is negligible as indicated by blank experiments of LAS in standard seawater without addition of sediment (Table 3 ). The LAS degradation in seawater in absence of sediment was shown in Figure6. Another possible cause of the loss of the surfactant, the sorption on the wall of the receptacle is negligible owing to its small value [7].

At the four stations (I, II, III and IV)

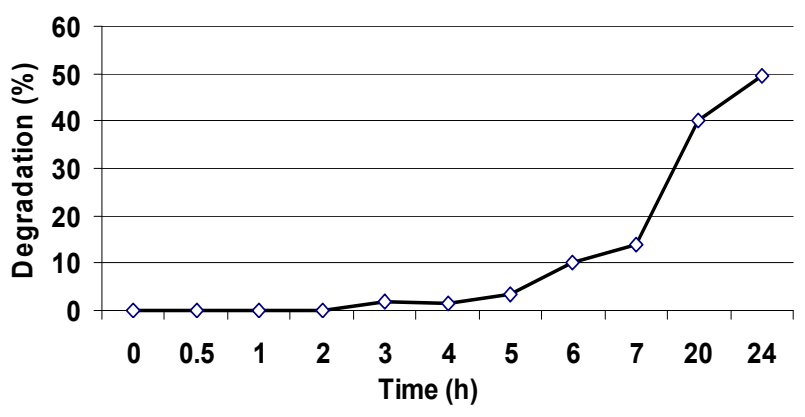

Figure 6. LAS degradation in seawater in absence of sediment.

\subsubsection{Isotherm Experiments}

Sorption data of linear alkylbenzene sulfonate (LAS) on sediment was obtained by Freundlich equation in log form as the following:

$$
\log (\mathrm{x} / \mathrm{m})=\log \mathrm{K}+1 / \mathrm{n} \log \mathrm{C}_{\mathrm{e}}
$$

where $\mathrm{x} / \mathrm{m}$ is the amount of LAS adsorbed per unit of adsorbent $\left(\mu \mathrm{gg}^{-1}\right), \mathrm{C}_{\mathrm{e}}$ is the equilibrium concentration of LAS in solution $\left(\mathrm{mgl}^{-1}\right), \mathrm{K}$ is a constant for the system, related to the bounding energy and can be defined as a sorption or distribution coefficient and represents the quantity of LAS adsorbed in $\mu \mathrm{gg}^{-1}$ (sediment) for a unit equilibrium concentration of the compound under test (i.e. $\mathrm{C}_{\mathrm{e}}=1$ ) and $1 / \mathrm{n}$ is a measure for the adsorption intensity. For $\mathrm{n}$ equal to 1 , the partition between the two phases is independent of the concentrations. Table 5 shows the adsorption data of LAS-seawater at a salinity of 36 PSU and a temperature of $25^{\circ} \mathrm{C}$, with the initial range of LAS concentrations $\left(\mathrm{C}_{\mathrm{i}}\right)$ lying between 1 and $100 \mathrm{mgl}^{-1}$ on four different sediment samples collected from El-Mex bay with different organic carbon content (ranged from 0.90 to $1.16 \%$ ). The concentration of LAS adsorbed $\left(\mathrm{C}_{\mathrm{ads}}\right)$ was determined by difference between the initial concentration $\left(\mathrm{C}_{\mathrm{i}}\right)$ and the equilibrium concentration $\left(\mathrm{C}_{\mathrm{e}}\right)$. All adsorption data were applied to the Freundlich equation and the plot of $\log \mathrm{x} / \mathrm{m}$ versus $\log \mathrm{C}_{\mathrm{e}}$ gave straight lines derived from regression analysis (Figure7). The amount of LAS desorbed from sediment during experimental run is negligible as indicated by blank experiments by determination of LAS in supernatant standard seawater without addition of LAS.

The Freundlich constants, $\mathrm{K}$ and $1 / \mathrm{n}$, were determined from the intercept and the slope, respectively, and are showed in Table 6 . The total organic matter content was $0.90,0.95,1.07$ and 1.16 for the four sediment samples I, II, III and IV, respectively. As shown in Table 6, the results revealed the increasing of LAS sorption on the sediments are coincided with the increasing of total organic carbon (TOC). The increase of $\mathrm{K}$-values (which is a measure of the energy bound between adsorbent and adsorbate) with increasing of organic matter content of the sediment is indicative of a hydrophobic interaction controlling the adsorption of LAS on sediments. A 
value of $1 / \mathrm{n}$ describes the degree of curvature of the isotherms. Increasing in $1 / \mathrm{n}$ values is indicative for a cooperative adsorption. It means a bonding mechanism in which an increasing surface coverage enhances the affinity of the surfactant for the surface. The values obtained for $1 / \mathrm{n}$ are less than 1 indicating an availability of sorption sites dependent on the solution concentration. The enhanced sorption observed in all isotherms may be attributed also to micelle formation at sediment surface. Inoue et al. (1978)[30] suggested that the micelle condensation depends on intermolecular association due to van der Waals forces which occur at higher concentrations of LAS.

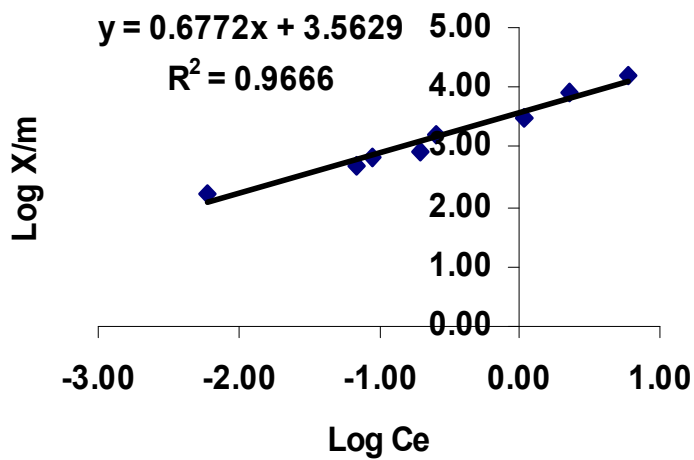

Station I

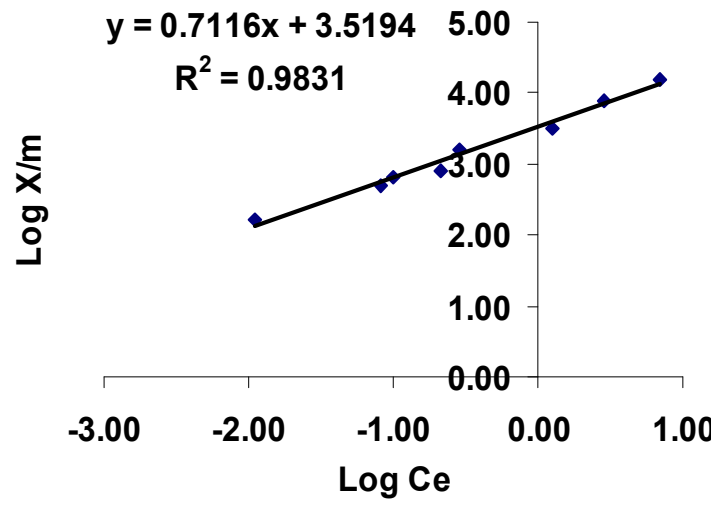

Station III

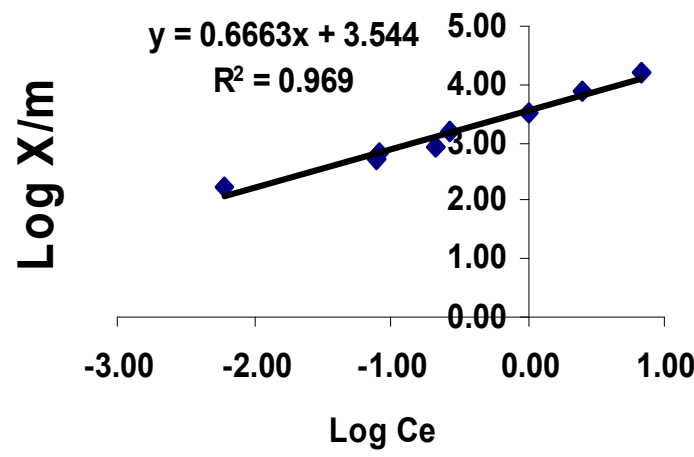

Station II

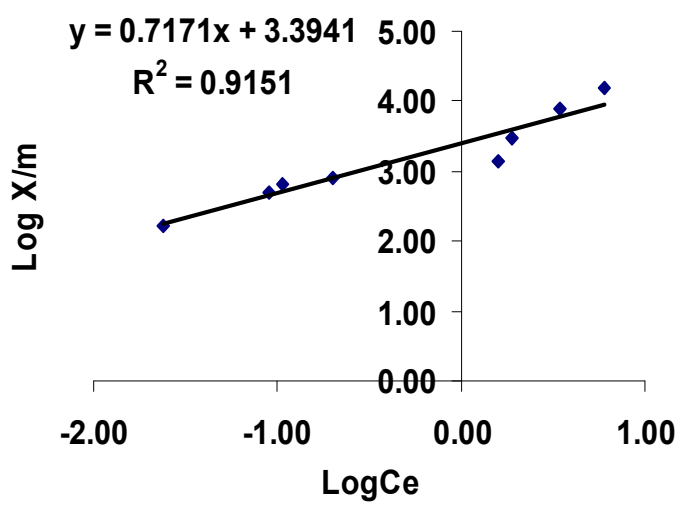

Station IV

Fig. 7. Linearization of Freundlich's isotherm for LAS sorption onto El-Mex Bay sediments at salinity 36 PSU and $25^{\circ} \mathrm{C}$.

Comparing the Freundlich constants obtained in the present study with the few data on adsorption of LAS on sediment in Literature [31], the values of $\mathrm{K}$ and $1 / \mathrm{n}$ are nearly equal to the reported values. Unlike sorption $(1 / \mathrm{n} \neq 1)$, the desorption isotherms were linear $(1 / \mathrm{n}=1)$, indicate partitioning of LAS sediment organic carbon and seawater. A similar phenomenon, i.e. non-linear sorption and linear desorption isotherms for LAS in fresh water sediments was observed [10]. Fytianos et al. (1998a) [[28] reported that LAS adsorption on soils correlated positively with the organic matter content. The amount of LAS sorbed on soils with higher content of organic matter was larger than on soils with less organic matter. The adsorption of LAS on El-Mex Bay sediments can not be fitted to the Langmuir isotherm indicating that the adsorption is localized in multilayer, thus the residence time of LAS in the sediment will be increase due to the adsorption of LAS on sediments becomes more easily. Adsorption data of LAS on El-Mex bay sediments can be also described by Stern-Graham equation previously used to describe the adsorption of LAS on river sediments [32] and adsorption of LAS homologues on sludge [33].

$$
\mathrm{X} / \mathrm{m}=\mathrm{K}^{*} \mathrm{C}_{\mathrm{e}}
$$

Where $\mathrm{K}^{*}$ is Stern-Graham constant corresponding to partition coefficient. The values of $\mathrm{K}^{*}$ in seawater evaluated from the least-squares lines for each of the adsorption isotherms on four sediment samples (Figure8) are 2731.7, 2382.6, 2337.6 and 2296 for sediment sample I, II, III and IV, respectively. The results that can be drawn from the $\mathrm{K}^{*}$-values are entirely comparable to those obtained in the discussion of Freundlich constant (K), i.e. sorption increases significantly as organic matter content of sediment increases due to the hydrophobic interaction between the alkyl chain and organic carbon content of the sediments.

The importance of sorption as one of the mechanisms involved in LAS removal from the marine water column, which may be affected by several factors such as chain length of LAS homologues, salinity and the total hardness of marine water. $\mathrm{pH}$ considered a one of most important factor which effect on the rate of adsorption of anionic surfactants on solid surfaces. To assess the effect of $\mathrm{pH}$ values on the sorption of LAS, experiments were conducted at three $\mathrm{pH}$ values in 
natural seawater (free from surfactants) with $\mathrm{pH} \mathrm{3.8,} 8.5$ and 12. A fixed amount ( $3.0 \mathrm{~g}$ ) of sediment collected from El-Mex bay, at the same four stations, contacted with $50 \mathrm{ml}$ of LAS solution in seawater ranged from 1 to $100 \mathrm{mgl}^{-1}$ with

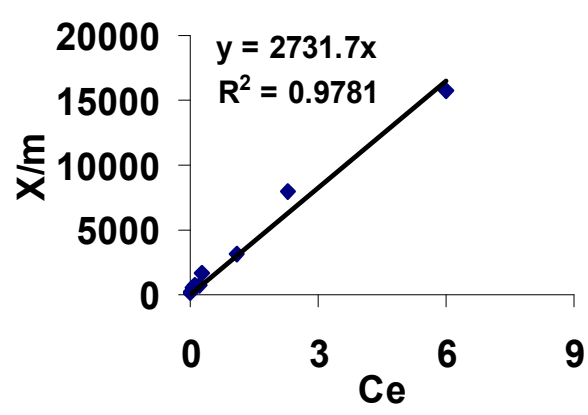

Station I

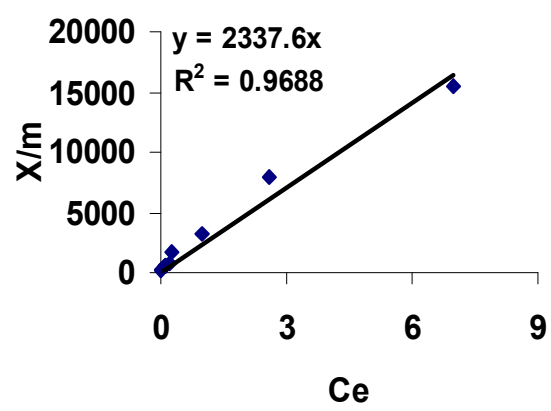

Station III

appropriate salinity, and the $\mathrm{pH}$ of the solution adjusted to the appropriate $\mathrm{pH}$ value using hydrochloric acid or sodium hydroxide solutions.

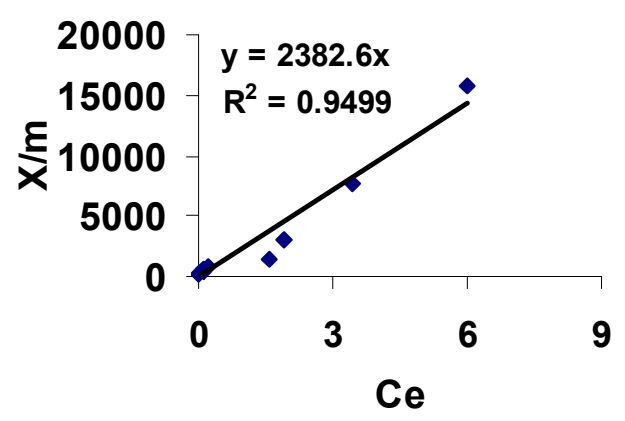

Station II

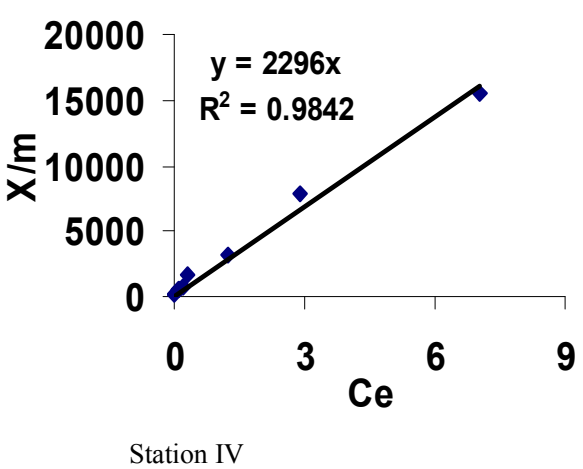

Fig. 8. Stern-Graham isotherm for LAS sorption onto El-Mex Bay sediments at salinity 36 PSU and $25^{\circ} \mathrm{C}$.

Sorption data of LAS on the sediments at the different $\mathrm{pH}$ were applied to Freundlich equation. The Freundlich constants $\mathrm{K}$ and $1 / \mathrm{n}$ that determined from the intercept and the slope respectively (Figure9) are showed in Tables 7 . The results appear that LAS sorption on sediments was strongly affected by $\mathrm{pH}$ and decreased with increasing $\mathrm{pH}$ for each sediment sample. The increase in the adsorption under acidic conditions may be based on the increase of the positive charge on colloidal surfaces [34]. This argument is based on the fact that the surfaces of El-Mex bay sediments carry negative charges because the grain size analysis showed that this sediment are coarse or medium sand, i.e., the surface will be rich with silica particles. Hence, if negatively charged molecules, such as LAS are to be bound to such a surface, appositively charged entity is needed as a bridge. If hydrogen ions are assumed to act in this capacity, the $\mathrm{pH}$ effects can be explained. The same pattern which based on surface-charge-based hypothesis has been reported for the sorption of humic acids by fungal biomass [35] and for the sorption of LAS by algal biomass [36].

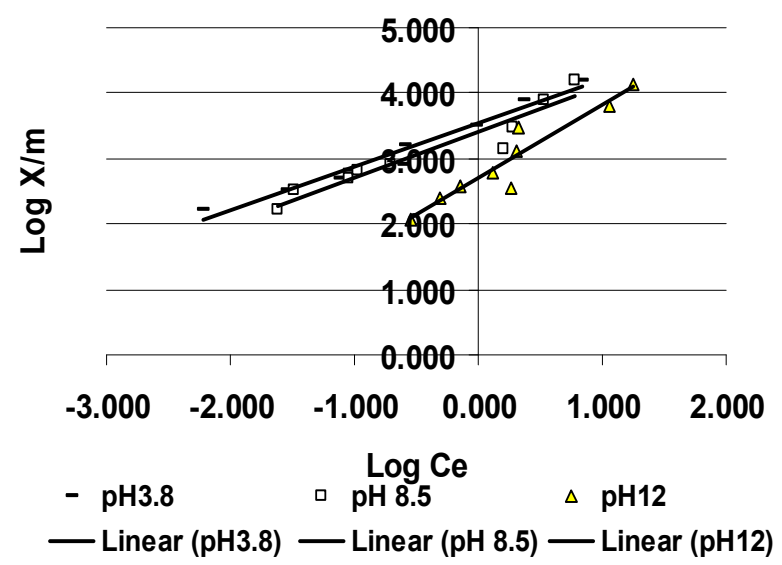

Station I

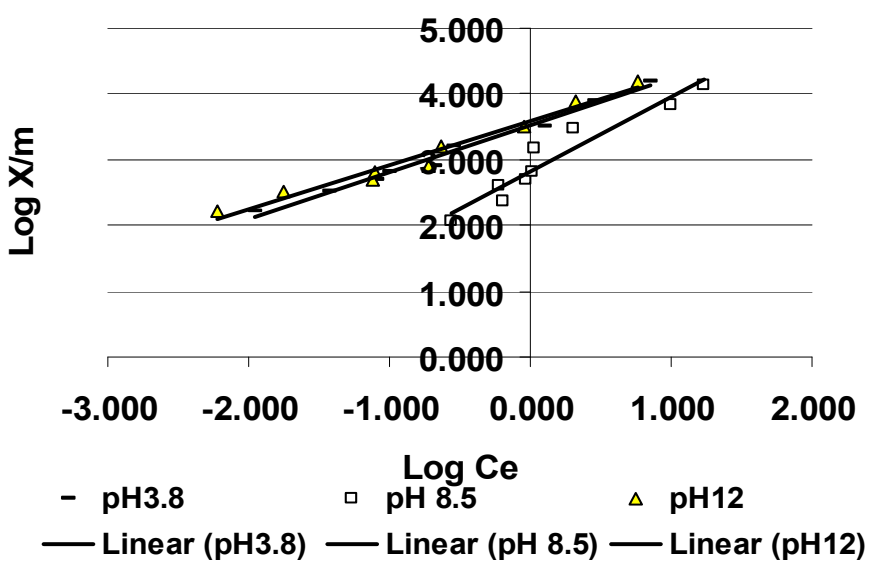

Station II 

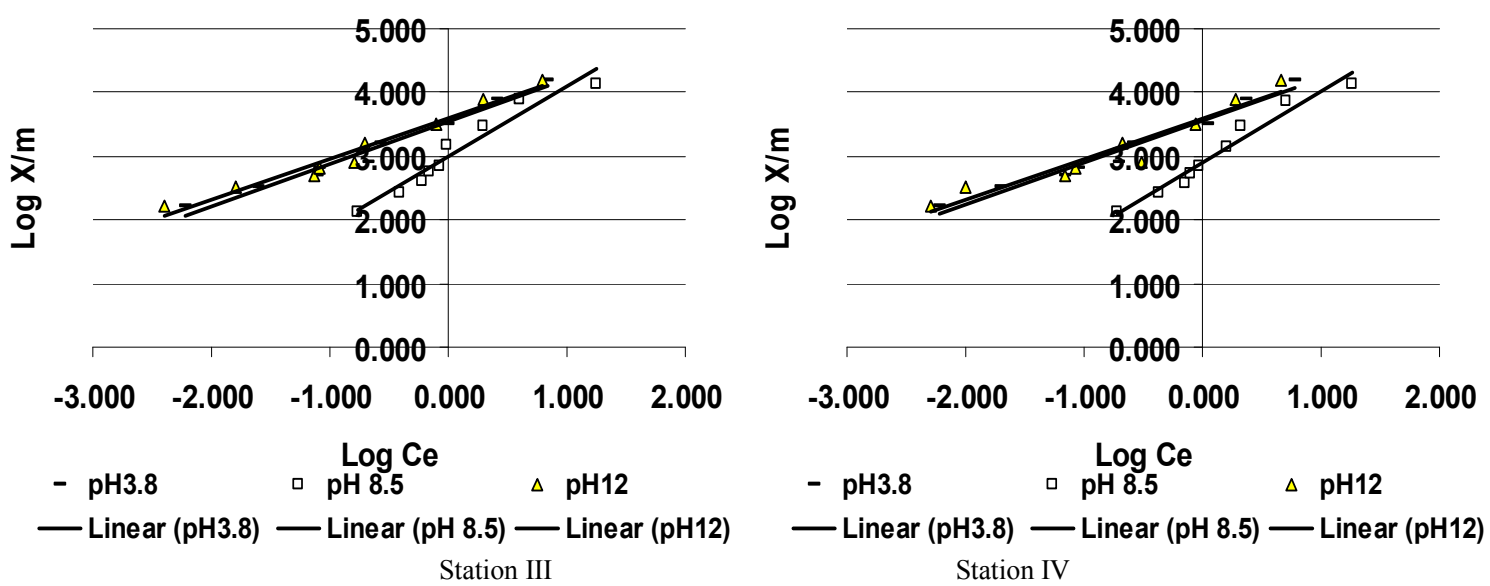

Fig. 9. Freundlich isotherms for LAS sorption by different El Mex Bay sediments in seawater at different pH values (3.8,8.5,12), salinity 36 PSU and temperature $25^{\circ} \mathrm{C}$

In addition, at low $\mathrm{pH}$ the LAS molecule is undissociated and, therefore, less hydrophilic than at high $\mathrm{pH}$, resulting in higher sorption onto sediment [28]. For sorption of LAS on sediment which undergoes hydroxylation and ionization, $\mathrm{pH}$ is a very important variable since it can be effect on the electrostatic interactions governing the sorption process [37]. Fytianos et al. (1998a) [28] reported that the LAS sorption on soils decreased with increasing $\mathrm{pH}$. The dependence of partition coefficient $\mathrm{K}$ on the organic matter content of the sediments can be explained in terms of hydrophobic interactions, and the dependence on $\mathrm{pH}$ can be attributed either to electrostatic interactions or to specific chemical interactions.

Table 1. Physicochemical characterization of Sediment and seawater of El-Mex Bay.

\begin{tabular}{|c|c|c|c|c|c|c|c|c|c|}
\hline \multirow{2}{*}{ St. } & \multicolumn{5}{|c|}{ Sediment characteristics } & \multicolumn{4}{|c|}{ Water characteristics } \\
\hline & pH & Eh & water Content $\%$ & $\mathrm{CaCO}_{3} \%$ & TOC $\%$ & pH & DO (mg/l) & Salinity (PSU) & LAS(mg/l) \\
\hline I & 7.31 & 104 & 79.29 & 88.27 & 1.16 & 7.74 & 1.27 & 3.89 & $0.17-0.40$ \\
\hline II & 7.56 & 208 & 77.49 & 91.66 & 1.07 & 7.82 & 1.98 & 5.00 & $0.07-0.10$ \\
\hline III & 7.72 & 197 & 72.27 & 95.54 & 0.95 & 8.14 & 2.02 & 38.58 & $0.04-0.09$ \\
\hline IV & 7.78 & 209 & 75.12 & 95.60 & 0.90 & 8.10 & 2.33 & 38.54 & $0.05-0.08$ \\
\hline
\end{tabular}

Table 2. Spatial distribution of LAS homologues concentration $(\mu \mathrm{g} / \mathrm{g})$ in El-Mex Bay sediment and its relative percentage from the total LAS homologues.

\begin{tabular}{llllllllll}
\hline \multirow{2}{*}{ St. } & \multicolumn{2}{l}{ LAS homologues $(\boldsymbol{\mu g} / \mathbf{g})$} & \multicolumn{5}{c}{ LAS homologues (\%) } \\
\cline { 2 - 11 } & $\mathbf{C}_{\mathbf{1 0}}$ & $\mathbf{C}_{\mathbf{1 1}}$ & $\mathbf{C}_{\mathbf{1 2}}$ & $\mathbf{C}_{\mathbf{1 3}}$ & Total & $\mathbf{C}_{\mathbf{1 0}}$ & $\mathbf{C}_{\mathbf{1 1}}$ & $\mathbf{C}_{\mathbf{1 2}}$ & $\mathbf{C}_{\mathbf{1 3}}$ \\
\hline I & ND & 0.450 & 0.047 & 0.043 & 0.540 & ND & 79.40 & 10.40 & 10.10 \\
II & ND & 0.312 & 0.041 & 0.040 & 0.393 & ND & 82.70 & 8.90 & 8.30 \\
III & ND & 0.315 & 0.034 & 0.032 & 0.381 & ND & 81.70 & 9.30 & 9.00 \\
IV & ND & 0.309 & 0.035 & 0.034 & 0.378 & ND & 83.30 & 8.70 & 7.90 \\
\hline
\end{tabular}

Table 3. LAS degradation in seawater in absence of sediment.

\begin{tabular}{lllll}
\hline Time (h) & $\mathbf{C i}$ & $\mathbf{C e}$ & $\mathbf{C}_{\text {degradation }}$ & Degradation \% \\
\hline 0 & 10 & 10.000 & 0 & 0 \\
0.5 & 10 & 9.983 & 0.017 & 0.17 \\
1 & 10 & 9.985 & 0.015 & 0.15 \\
2 & 10 & 9.988 & 0.012 & 0.12 \\
3 & 10 & 9.820 & 0.18 & 1.8 \\
4 & 10 & 9.847 & 0.153 & 1.53 \\
5 & 10 & 9.651 & 0.349 & 3.49 \\
6 & 10 & 8.982 & 1.018 & 10.18 \\
7 & 10 & 8.601 & 1.399 & 13.99 \\
20 & 10 & 5.982 & 4.018 & 40.18 \\
24 & 10 & 5.054 & 4.946 & 49.46 \\
\hline
\end{tabular}


Table 4. LAS Adsorption Rate onto El-Mex bay sediments.

\begin{tabular}{|c|c|c|c|c|c|}
\hline & Time (h) & $C_{i}(\mu g / m l)$ & $\mathrm{C}_{\mathrm{e}}(\mu \mathrm{g} / \mathrm{ml})$ & $\mathrm{C}_{\text {ads }}(\mu \mathrm{g} / \mathrm{ml})$ & Sorption \% \\
\hline \multirow{7}{*}{ I } & 0 & 10 & 10.000 & 0.000 & 0.00 \\
\hline & 1 & 10 & 1.570 & 8.430 & 84.30 \\
\hline & 2 & 10 & 1.308 & 8.692 & 86.92 \\
\hline & 3 & 10 & 1.209 & 8.791 & 87.91 \\
\hline & 4 & 10 & 1.210 & 8.790 & 87.90 \\
\hline & 5 & 10 & 1.203 & 8.797 & 87.97 \\
\hline & 6 & 10 & 1.180 & 8.820 & 88.20 \\
\hline \multirow{7}{*}{ II } & 0 & 10 & 10.000 & 0.000 & 0.00 \\
\hline & 1 & 10 & 1.630 & 8.370 & 83.70 \\
\hline & 2 & 10 & 1.310 & 8.690 & 86.90 \\
\hline & 3 & 10 & 1.207 & 8.793 & 87.93 \\
\hline & 4 & 10 & 1.210 & 8.790 & 87.90 \\
\hline & 5 & 10 & 1.208 & 8.792 & 87.92 \\
\hline & 6 & 10 & 1.200 & 8.800 & 88.00 \\
\hline \multirow{7}{*}{ III } & 0 & 10 & 10.000 & 0.000 & 0.00 \\
\hline & 1 & 10 & 1.650 & 8.350 & 83.50 \\
\hline & 2 & 10 & 1.380 & 8.620 & 86.20 \\
\hline & 3 & 10 & 1.210 & 8.790 & 87.90 \\
\hline & 4 & 10 & 1.210 & 8.790 & 87.90 \\
\hline & 5 & 10 & 1.208 & 8.792 & 87.92 \\
\hline & 6 & 10 & 1.174 & 8.826 & 88.26 \\
\hline \multirow{7}{*}{ IV } & 0 & 10 & 10.000 & 0.000 & 0.00 \\
\hline & 1 & 10 & 1.630 & 8.370 & 83.70 \\
\hline & 2 & 10 & 1.400 & 8.600 & 86.00 \\
\hline & 3 & 10 & 1.210 & 8.790 & 87.90 \\
\hline & 4 & 10 & 1.209 & 8.791 & 87.91 \\
\hline & 5 & 10 & 1.190 & 8.810 & 88.10 \\
\hline & 6 & 10 & 1.135 & 8.865 & 88.65 \\
\hline
\end{tabular}

Table 5. LAS-seawater Adsorption data onto different sediment samples from El-Mex bay with different total organic carbon content (TOC) at salinity36 PSU and $25^{\circ} \mathrm{C}$.

\begin{tabular}{|c|c|c|c|c|c|}
\hline Sample No & $C_{i}(\mu \mathrm{g} / \mathrm{ml})$ & $C_{e}(\mu \mathrm{g} / \mathrm{ml})$ & $\mathrm{C}_{\text {ads }}(\mu \mathrm{g} / \mathrm{ml})$ & $X / m(\mu g / g)$ & TOC (\%) \\
\hline \multirow{8}{*}{ I } & 1 & 0.024 & 0.976 & 162.667 & \multirow{8}{*}{1.16} \\
\hline & 3 & 0.089 & 2.911 & 485.167 & \\
\hline & 4 & 0.106 & 3.894 & 649.000 & \\
\hline & 5 & 0.198 & 4.802 & 800.333 & \\
\hline & 10 & 1.600 & 8.400 & 1400.000 & \\
\hline & 20 & 1.900 & 18.100 & 3016.667 & \\
\hline & 50 & 3.419 & 46.581 & 7763.500 & \\
\hline & 100 & 6.023 & 93.977 & 15662.833 & \\
\hline \multirow{8}{*}{ II } & 1 & 0.011 & 0.989 & 164.833 & \multirow{8}{*}{1.07} \\
\hline & 3 & 0.081 & 2.919 & 486.500 & \\
\hline & 4 & 0.100 & 3.900 & 650.000 & \\
\hline & 5 & 0.210 & 4.790 & 798.333 & \\
\hline & 10 & 0.290 & 9.710 & 1618.333 & \\
\hline & 20 & 1.254 & 18.746 & 3124.333 & \\
\hline & 50 & 2.892 & 47.108 & 7851.333 & \\
\hline & 100 & 7.012 & 92.988 & 15498.000 & \\
\hline \multirow{8}{*}{ III } & 1 & 0.006 & 0.994 & 165.667 & \multirow{8}{*}{0.95} \\
\hline & 3 & 0.080 & 2.920 & 486.667 & \\
\hline & 4 & 0.081 & 3.919 & 653.167 & \\
\hline & 5 & 0.210 & 4.790 & 798.333 & \\
\hline & 10 & 0.270 & 9.730 & 1621.667 & \\
\hline & 20 & 1.008 & 18.992 & 3165.333 & \\
\hline & 50 & 2.580 & 47.420 & 7903.333 & \\
\hline & 100 & 7.000 & 93.000 & 15500.000 & \\
\hline \multirow{8}{*}{ IV } & 1 & 0.006 & 0.994 & 165.667 & \multirow{8}{*}{0.90} \\
\hline & 3 & 0.070 & 2.930 & 488.333 & \\
\hline & 4 & 0.089 & 3.911 & 651.833 & \\
\hline & 5 & 0.200 & 4.800 & 800.000 & \\
\hline & 10 & 0.255 & 9.745 & 1624.167 & \\
\hline & 20 & 1.100 & 18.900 & 3150.000 & \\
\hline & 50 & 2.300 & 47.700 & 7950.000 & \\
\hline & 100 & 6.000 & 94.000 & 15666.667 & \\
\hline
\end{tabular}


Table 6. Effect of sediment organic matter content (TOC) on the LAS sorption.

\begin{tabular}{lllll}
\hline Sample No & TOC (w/w) & Log K & $\mathbf{1 / n}$ & $\mathbf{R}^{2}$ \\
\hline I & 1.16 & 3.563 & 0.677 & 0.967 \\
II & 1.07 & 3.541 & 0.666 & 0.969 \\
III & 0.95 & 3.519 & 0.712 & 0.986 \\
IV & 0.90 & 3.394 & 0.717 & 0.915 \\
\hline
\end{tabular}

Table 7. pH Effect on LAS sorption onto different sediment samples from El-Mex bay with salinity $36 \mathrm{PSU}$ at $25^{\circ} \mathrm{C}$.

\begin{tabular}{llllll}
\hline Sample No & TOC (\%) & $\mathbf{p H}$ & $\mathbf{K}$ & $\mathbf{1 / n}$ & $\mathbf{R}^{\mathbf{2}}$ \\
\hline \multirow{3}{*}{ I } & \multirow{3}{*}{1.16} & 12 & 38.77 & 0.682 & 0.962 \\
& & 8.5 & 252.12 & 0.688 & 0.917 \\
& & 3.8 & 351.08 & 0.672 & 0.964 \\
II & \multirow{2}{*}{1.07} & 12 & 45.06 & 0.697 & 0.971 \\
& & 8.5 & 331.05 & 0.71 & 0.985 \\
& & 3.8 & 388.42 & 0.67 & 0.968 \\
III & \multirow{2}{*}{0.95} & 8.5 & 35.051 & 0.644 & 0.988 \\
& & 3.8 & 409.07 & 0.661 & 0.972 \\
& & 12 & 52.071 & 0.631 & 0.963 \\
IV & \multirow{2}{*}{0.90} & 8.5 & 367.11 & 0.663 & 0.977 \\
& & 3.8 & 387.61 & 0.635 & 0.968 \\
\hline
\end{tabular}

\section{Conclusion}

The sorption behaviors of LAS on El-Mex Bay sediments were studied. Based on the data presented in this work, the following conclusions are drawn: The sorption of LAS on the bay sediments is satisfactory described by the Freundlich and Stern-Graham isotherm equation indicating that the adsorption is localized in multilayer, thus the residence time of LAS in the sediment will be increase due to the adsorption of LAS on sediments becomes more easily. Sorption increases significantly as organic matter content of sediment increases due to the hydrophobic interaction between the alkyl chain and organic carbon content of sediment. LAS sorption on sediments was strongly affected by $\mathrm{pH}$ and decreased with increasing $\mathrm{pH}$ for each sediment sample which can be attributed either to electrostatic interactions or to specific chemical interactions.

\section{References}

[1] Ying, G.G. (2006). Fate, behavior and effects of surfactants and their degradation products in the environment, Environment International 32: $417-431$.

[2] Brackmann, B., \& Hager, C.D. (2004). The statistical world of raw material, fatty alcohols and surfactants. CESIO 6th World Surfactant Congress, Berlin, June 20-23.

[3] Verge, C., Moreno, A., Bravo, J., \& Berna, J.L. (2000). Influence of water hardness on the bioavailability and toxicity of linear alkylbenzene sulphonate (LAS). Chemosphere. 44:1749-1757.

[4] Abd-Allah, A.M.A. (1995). Determination of long-chain alkylbenzenes in sediment samples from Alexandria coast, Egypt. Toxicological and Environmental Chemistry 47:83-8.
[5] Holt, M.S., \& Bernstein, S.L. (1992). Linear alkylbenzenes in sewage sludges and sludge amended soils. Water Res. 26:613-624.

[6] Painter, H.A. (1992).Anionic surfactants. Handbook Environ. Chem. 3:2-88.

[7] Gómez-Parra, A., Rubio, J.A., \& González-Mazo, E. (1996). Sorption of linear alkylbenzenesulfonates (LAS) on marine sediment. Marine Chemistry 54:171-177.

[8] Amano, K. \& Fukushima, T. (1993). Partitioning of linear alkylbenzene sulphonates in natural water and sediment. J. Environ. Sci. Health. 28(A):683-696.

[9] Amano, K., Fukushima, T., \& Nakasugi, O. (1992). Diffusion exchange of linear alkylbenzene sulphonates (LAS) between overlying water and bottom sediment. Hydrobiologia 235/236:491-499.

[10] Matthijs, E., and De Henau, H. (1985). Adsorption and desorption of LAS. Tenside Detergents 22:299-304.

[11] Liu, Z., Edwards, A., \& Luthy, R.G. (1992). Non-ionic surfactant sorption onto soil. Water Sci. Technol. 26:2337-2340.

[12] Hand, V.C., \& Williams, G.K. (1987). Structure-activity relationships for sorption of linear alkylbenzenesulfonate. Environ. Sci. Technol. 21:370-373.

[13] Di Toro, D.M., Dodge, L.J., \& Hand, V.C. (1990). A model for anionic surfactant sorption. Environ. Sci. Technol. 24:1013-1020.

[14] Hand, V.C., Rapaport, R.A., \& Pittinger, C.A. (1990). First validation of a model for the sorption of linear alkylbenzene sulphonate (LAS) to sediment and comparison to chronic effects data. Chemosphere 21:741-750.

[15] Takada, H., \& Ogura, N. (1992). Removal of linear alkylbenzene sulphonates (LAS) in the Tamagawa Estuary. Marine Chemistry 37:257-273.

[16] de Henau, H., Mathijs, E., \& Hopping, W.D. (1986). Linear alkylbenzene sulfonates (LAS) in sewage sludges, soils, and sediments: analytical determination and environmental safety considerations. Int. J. Environ. Anal. Chem. 26:279-293.

[17] Baruah, T. C., and Barthakur, H. P. (1997). A Textbook of Soil Analysis, Vikas Publishing House, Pvt. Ltd., New Delhi, India.

[18] Koga, M., Yamamichi, Y., Nomoto, Y., Irie, M., Tanimura, T., \& Yoshinaga, T. (1999). Rapid determination of anionic surfactants by improved spectrophotometric method using methylene blue. Ana. Sci. 15:563-568.

[19] Akyüz, M, \& Robers, D.J. (2002). Determination of linear alkylbenzene sulphonates and their biodegradation intermediated by isocratic RP-HPLC. Turk J. Chem. 26:669-679.

[20] Gonzalez-Mazo, E., Honing, M., Barcelo, D., \& Gomez-Parra, A. (1997). Monitoring long-chain intermediate products from the degradation of linear alkylbenzene sulphonates in the marine environment by solid-phase extraction followed by liquid chromatography/ ionspray mass spectrometry. Environ. Sci. Technol. 31:504-510. 
[21] Comellas, L., Portillo, J.L., and Vaquero, M.T. (1993). Development of an analytical procedure to study linear alkylbenzenesulphonate (LAS) degradation in sewage sludge-amended soils. Journal of Chromatography A 657: 25-31.

[22] Ahel, M. \& Terzic, S. (2003). Biogeochemistry of aromatic surfactants in microtidal estuaries. Chimia 57: 550-555

[23] González-Mazo, E., Gómez-Parra, A., León, V.M., and Sàez, M. (2002). Occurrence and distribution of linear alkylbenzene sulfonates and sulfophenylcarboxylic acids in several Iberian littoral ecosystems. Sci. Total Environ. 288:215-226.

[24] Terzic, S., and Ahel, M. (1994). Input and behaviour of linear alkylbenzenesulphonates (LAS) in a stratified estuary. Mar. Pollut. Bull. 28:735-740.

[25] González-Mazo, E., Forja, J.M. \& Gómez-Parra, A. (1998). Fate and distribution of linear alkylbenzene sulfonates in the littoral environment. Environ. Sci. Technol. 32:1636-1641

[26] Elsgaard, L., Pojana, G., Miraval, T., Eriksen, J., \& Marcomini, A. (2003). Biodegradation of linear alkylbenzene sulfonates in sulfate-leached soil mesocosms. Chemosphere. 50:929-937.

[27] Marcomini, A., Capel, P.D., Lichtensteiger, Th.., Brunner, P.H., \& Giger, W. (1989). Behavior of aromatic surfactants and PCBs in sludge-treated soil and landfills. J. Environ. Qual. 18:523-528.

[28] Fytianos, K., Voudrias, E., \& Papamichali, A. (1998a). Behaviour and fate of linear alkylbenzene sulphonate in different soils. Chemosphere 36:2741-2746.

[29] Kordel, W., Hennecke, D., \& Franke, C. (1997). Determination of the adsorption-coefficients of organic substances on sewage sludges. Chemosphere 35:107-119.

[30] Inoue, K., Kaneko, K., \& Yoshida, M. (1978). Adsorption of dodecylbenzenesulfonates by soil colloids and influence of soil colloids on their degradation. Soil Sci. Plant Nutr. 24:91-102.

[31] Fytianos, K., Voudrias, E., \& Mouratidou, T.H. (1998b). The sorption-desorption behaviour of linear alkylbenzene sulphonate in marine sediments. Chemosphere 36:2067-2074.

[32] Marchesi, J.R., House, W.A., White, G.F., Russell, N.J., \& Farr, I.S. (1991). A comparative study of the adsorption of linear alkyl sulphates and alkylbenzene sulphonates on river sediments. Colloid Surf. 53:63-78.

[33] Garcĺa, M.T., Campos, E., Dalmau, M., Ribosa, I., \& Sánchez-Leal, J. (2002). Structure-activity relationships for association of linear alkylbenzene sulphonates with activated sludge. Chemosphere 49:279-286.

[34] Siracuse, P., \& Somasundaran, P. (1986). Adsorption-desorption and hysteresis of sulfonates on kaolinite pH effects. J. Colloid Interface Sci. 114:183-193.

[35] Zhou, J.L., \& Banks, C.J. (1992). Humic acid removal from water by biosorption. Environ. Technol. 13:727-738.

[36] Forster, C.F., Mehrotra, I., \& Alibhai, K.R.K. (1985). The multiple binding of heavy metals by digested sludge. J. Chem. Technol. Biotechnol. 35:145-154.

[37] Scamehorn, J. F.; Schechter, R. S. \& Wade, W. H. (1982). Adsorption of Surfactants on Mineral Oxide Surfaces from Aqueous Solutions. I. Isomerically Pure Anionic Surfactants, J. Colloid Interface Sci. 85, $463-478$. 